\title{
NÓS, OS DESCONHECIDOS (2012)
}

Tamy de Macedo PIMENTA ${ }^{1}$

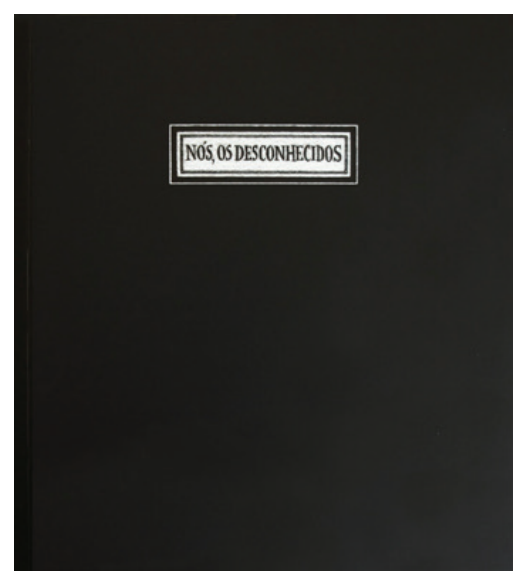

A aura acena pela última vez na expressão fugaz de um rosto, nas antigas fotos. É o que lhes dá sua beleza melancólica e incomparável. (BENJAMIN, 1985, p. 174) ${ }^{2}$

Nós, os desconhecidos é um livro organizado por Rui Pires $\mathrm{Cabral}^{3}$ e pela ilustradora Daniela Gomes, editado pela Averno, de Lisboa. É composto, no total, por vinte e seis poemas de escritores contemporâneos, sendo eles, em sua maioria, poetas cujas primeiras publicações datam dos anos 80 em diante. Entretanto, há exceções, como demonstra, por exemplo,

\footnotetext{
${ }^{1}$ UFF/FAPERJ

${ }^{2}$ BENJAMIN, Walter. A obra de arte na era de sua reprodutibilidade técnica. Obras escolhidas, v.I, São Paulo: Brasiliense, 1985.

${ }^{3}$ Poeta e tradutor nascido em 1967. Seu primeiro livro de poesia, Pensão Bellinzona e Outros Poemas, data de 1994, a que se seguiram nove títulos.
} 
a presença de A. M. Pires Cabral (pai de Rui Pires Cabral, cujo primeiro livro de poesia data de 1974).

Como explicitado na "Nota Prévia" da obra, a proposta foi escrever poemas a partir de fotografias antigas de anônimos, que são "[...] se tivermos o vagar e o cuidado de lhes dispensarmos mais do que uma olhadela distraída, um rico manancial para a imaginação" (CABRAL,

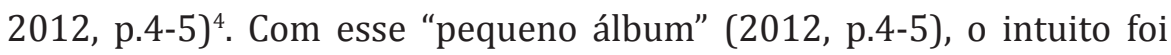
resgatar alguns desses desconhecidos encontrados em antiquários e dar-lhes um abrigo, "uma espécie de segunda vida" (2012, p.4-5), por meio dos versos neles inspirados. Dessa maneira, a poesia aparece como uma possibilidade de salvação do completo esquecimento em que esses desconhecidos estavam mergulhados, apesar dos poetas saberem que esta salvação também tem seu prazo, já que "tudo, como sabemos, é por enquanto" (2012, p. 4-5, grifo nosso).

As fotografias são todas em preto e branco e geralmente possuem marcas de deterioração pelo tempo. Nelas há a presença de seres “de carne e osso" (2012, p.46-47) e se digo seres é pelo fato de, entre rostos de pessoas, se encontrarem também as caras de animais; notavelmente na foto que inspirou "Cão Estrangeiro", de Ricardo Álvaro.

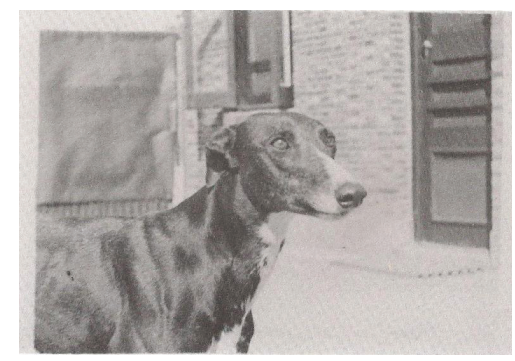

\section{CÃO ESTRANGEIRO}

Escrevo-te, cão desconhecido, estrangeiro, da belíssima raça dos

últimos, criatura estelar e sem dono, que viste boquiaberto o clarão

dos fogos celestes e uivaste à aurora do real, que desenterraste

das ruínas, do pó e cinza dos séculos, o grande osso do criador e

o abocanhaste com assombro, que afogaste a tua sede inclinado

sobre os abismos da beleza, com a cabeça ourada, a andar à roda

\footnotetext{
${ }^{4}$ As páginas de número par do livro contêm as fotos, seguidas pelos poemas, nas páginas ímpares seguintes.
} 
na lotaria dos dias e das noites, Oh canção da mais bela bebedeira!, que amaste de muito perto, com a cauda trilhada nas violentas

portas batidas do abandono, que desconheces a gravidade, os

movimentos terrestres e erraste com precisão pelos desertos do mundo, orientado pelo candelabro da noite, com o pêlo exposto

ao hálito das estações, que cerraste os dentes contra o açaime e a

coleira da obediência, ao arrepio da matilha, que espantaste o gado cabisbaixo e mijaste nas monstruosas paredes dos matadouros, contra a suave brisa da vidinha. [...] (p.70-71)

Os versos endereçam-se ao "cão desconhecido, estrangeiro" - o "tu" do poema -, cuja imagem funciona quase como uma dedicatória. Assim, o poeta responde ao olhar do animal, escrevendo-lhe. Segundo Benjamin (1989), é

[...] inerente ao olhar a expectativa de ser correspondido por quem o recebe. Quem é visto, ou acredita estar sendo visto, revida o olhar. Perceber a aura de uma coisa significa investila do poder de revidar o olhar (BENJAMIN, 1989, p.139-140) ${ }^{5}$.

Desse modo, não só no poema de Álvaro, mas em vários trabalhos presentes em Nós, os desconhecidos, existe um jogo de olhar/revidar; o olhar entre o poeta e o ser fotografado, uma vez que este olha de volta para quem o olha, enquanto quem o observa também revida o olhar ${ }^{5}$ BENJAMIN, Walter. Sobre alguns temas em Baudelaire. Obras escolhidas, v.III, São Paulo: Brasiliense, 1989. 
recebido, acredito, duplamente, já que olha e escreve. A poesia seria, então, um segundo olhar que, por sua vez, dá abertura a um terceiro - o de quem a lê. Acredito ser um belo exemplo disso o poema "Lady Midnight" de Manuel de Freitas ${ }^{6}$, em que a misteriosa mulher do retrato "parece querer ferir a moldura, num apelo mudo" (CABRAL, 2012, p.5455):

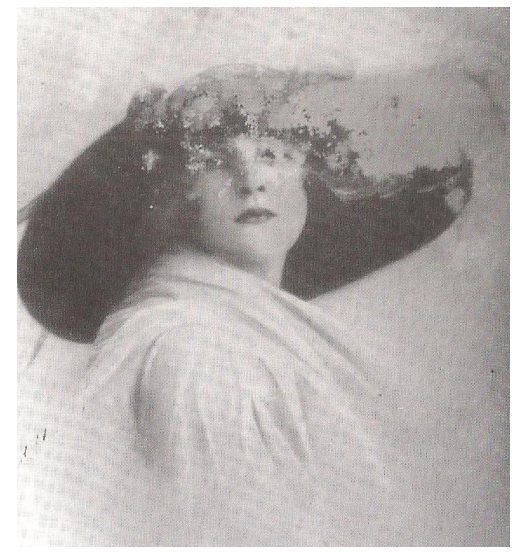

\section{LADY MIDNIGHT}

Acompanha-me há mais de vinte anos. Lembro-me de uma vez ter escrito algumas estrofes a partir do seu $<<$ rosto de despovoadas noites $>>$ (foi o único versos que fixei, tão mau como o resto do poema, que entretanto deitei fora).

Volto agora a olhar para esse rosto - menos envelhecido do que o meu, apesar das manchas de álcool e humildade que lhe esbatem, noite após noite, o chapéu negro.

O ombro, sublinhando uma pose obsoleta, parece querer ferir a moldura, num apelo mudo.

(p. 54-55)

Nos exemplos citados, ao devolver o olhar, o eu-poeta surge como um narrador que tenta inventar um roteiro, uma história por trás daqueles anônimos que os fitam. Entretanto, há poemas em que o sujeito-lírico e o sujeito fotografado se fundem, como nos versos de Rui Pires Cabral:

\footnotetext{
${ }^{6}$ Manuel de Freitas é um editor e poeta nascido em 1972. Seu primeiro livro, Todos contentes e eu também, foi publicado em 2000. Dois anos depois, ele organizou a antologia Poetas sem Qualidades (2002).
} 


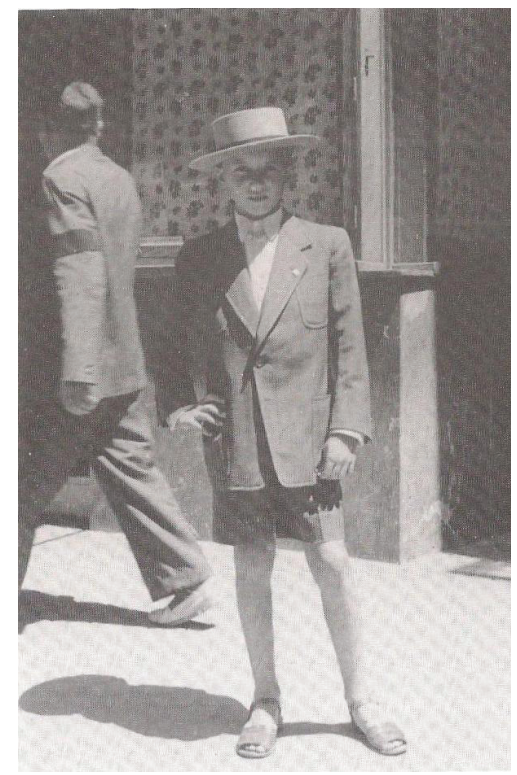

\section{VERSOS}

Sim, estive nessa rua

à hora incerta, de costas

para os avisos da morte

que já então me cobiçava.

Fui pequeno, confiante,

tive um chapéu de palha,

aprendi a tabuada. A noite

roubou-me a voz, a sorte

deu-me estes versos, 1 x 10

igual a nada.

(p. 86-87)

Nesse caso, o eu-lírico aparece como uma voz envelhecida que reflete a partir da observação de si mesmo em uma fotografia da infância. Em outro poema, de Emanuel Jorge Botelho, ocorre uma mudança de voz, de um eu-narrador que descreve cenas imaginadas para um eu que, de repente, identifica-se com um menino na fotografia: "eu fiquei de costas, como sempre" (CABRAL, 2012, p.30-31).

Nos exemplos acima, os poemas esboçam histórias, criando roteiros para os personagens reais fixados pela câmera. Há outros, porém, que, ao invés disso, problematizam a própria função do seu fazer poético diante dessas imagens, como magnificamente nos mostra Diogo Vaz Pinto7:

\footnotetext{
Pudesse, como o vento, arrastar

o meu silêncio impressionado sobre a imagem, sem a agredir com o rumor obsceno das
}

\footnotetext{
${ }^{7}$ Poeta nascido em 1985, cujo primeiro livro, Nervos, data de 2011. Juntamente com o também poeta David Teles Pereira, dirige a Revista Criatura.
} 


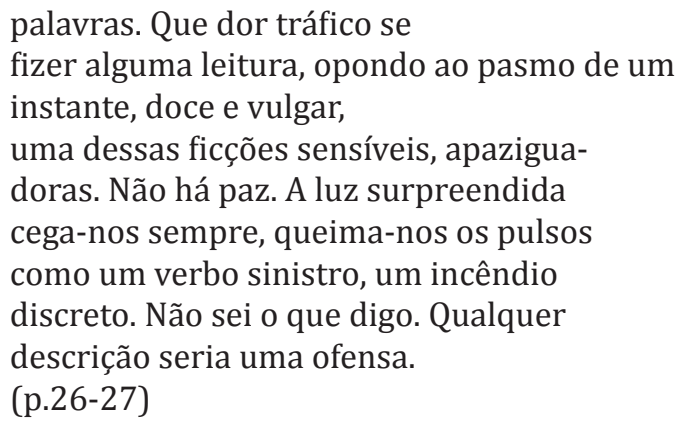

Sendo "já lugar-comum reconhecer que as imagens valem mais do que as palavras" (CABRAL, 2012, p.78-79), resta ao eu-poeta reconhecer sua incapacidade de dizer o invisível na fotografia, que aponta justamente "a presença na imagem daquilo que não se pode ver [...] aquilo que nunca se percebe diretamente no rosto" (PEIXOTO, 1996, p.51) ${ }^{8}$.

Uma estratégia de fuga dessa tensão é precisamente não dizer os retratos, mas questioná-los. Assim, fazendo perguntas aos rostos que os fitam, os poetas demonstram a impotência da poesia ao tentar dizer o indizível, refletindo acerca dos questionamentos que nos assaltam ao sermos surpreendidos por esses anônimos congelados:
Quem és tu, por trás da sombra, nesta foto rejeitada que chegou à minha mão?
Como eram os teus sonhos? Quem te amou?
Quem te chora desde o dia em que morreste?
(p.90-91)

Também se observa na passagem acima algo que percorre muitas das páginas desta obra: A caracterização desses seres como mortos. Para Susan Sontag, todas as fotos são um lembrete da morte (SONTAG, $2010)^{9}$, na medida em que, capturando um instante, elas indicam a

\footnotetext{
${ }^{8}$ PEIXOTO, Nelson Brissac. Paisagens urbanas. São Paulo: Editora SENAC São Paulo, 1996. ${ }^{9}$ SONTAG, Susan. Sobre fotografia. Trad. Rubens Figueiredo. São Paulo: Companhia das
} 
passagem contínua do tempo. Acredito que essa relação entre arte fotográfica e morte seja ainda mais forte em retratos que indicam, por seu próprio estado, sua antiguidade, como nas de Nós, os desconhecidos. Dessa forma, não são raras as menções a "sombras", "túmulos" e outros elementos ligados à "máquina insegura/ e mal oleada a que chamamos tempo" (CABRAL, 2012, p.8-9).

Nós, os desconhecidos, portanto, é fonte de belas fotografias e poemas que tentam com elas dialogar, seja dando a essas pessoas "uma casa nova" (2012, p.4-5) por meio de relatos imaginados ou intrigandose, interrogando seus misteriosos rostos. De formas variadas - o livro contém de poemas curtos a poemas em prosa - estes vinte e seis escritores compartilham sua comoção por "esta gente desconhecida, extraviada" que são, como nós, "matéria friável na correnteza dos dias" (CABRAL, 2012, p.4-5).

Letras, 2010. 